\title{
HUBUNGAN MANAJEMEN WAKTU DENGAN REGULASI DIRI DALAM BELAJAR PADA MAHASISWA FAKULTAS KEDOKTERAN UNIVERSITAS MALAHAYATI
}

\author{
Eunike Yulita Simaremare, Vira Sandayanti, Eka Silvia \\ Fakultas Kedokteran Universitas Malahayati \\ eunike.yulita31@gmail.com
}

\begin{abstract}
ABSTRAK
Regulasi diri dalam belajar merupakan hal yang sangat penting bagi mahasiswa dalam proses belajar. Manajemen waktu merupakan salah satu faktor yang mempengaruhi regulasi diri dalam belajar pada mahasiswa. Penelitian ini bertujuan untuk mengetahui hubungan manajemen waktu dengan regulasi diri dalam belajar pada mahasiswa Fakultas Kedokteran Universitas Malahayati. Penelitian ini merupakan penelitian kuantitatif korelasional. Penelitian ini dilaksanakan di Universitas Malahayati. Subjek penelitian berjumlah 123 mahasiswa. Teknik sampling yang digunakan adalah random sampling. Regulasi diri dalam belajar diukur dengan skala Motivated Strategies for Learning Quetionnaire (MSLQ). Skala ini mempunyai 36 item valid dengan nilai reliabilitas sebesar 0,897. Sedangkan manajemen waktu diukur dengan skala Time Management Questionnaire (TMQ). Skala ini mempunyai 16 item valid dengan nilai reliabilitas sebesar 0,85. Uji korelasi menggunakan teknik korelasi product moment yang dikerjakan menggunakan bantuan program SPSS 20 for windows. Hasil penelitian menunjukkan bahwa terdapat hubungan positif antara manajemen waktu dengan regulasi diri dalam belajar. Korelasi antara manajemen waktu dengan regulasi diri dalam belajar diperoleh koefisien $r=0,519$ dengan signifikansi atau $\mathrm{p}=0,000$. Hal tersebut menunjukkan bahwa ada hubungan positif yang signifikan antara manajemen waktu dengan regulasi diri dalam belajar pada mahasiswa Fakultas Kedokteran Universitas Malahayati.
\end{abstract}

Kata kunci : manajemen waktu, regulasi diri dalam belajar

\section{TIME MANAGEMENT RELATIONSHIP WITH SELF-REGULATION IN LEARNING IN FACULTY OF MEDICINE STUDENTS OF MALAHAYATI UNIVERSITY}

\section{ABSTRACT}

Self regulated learning are the important thing for students in the learning process. Time management are one of the factors that influence self-regulated leraning. This study aims to determine the relation from time management with self regulatied learning at medical student of Malahayati University. The research is a quantitative correlational study. The research was conducted at Malahayati University. Subject research totaled 123 students. The sampling techniques for used was a random sampling. Self regulated learning is measured by the scale of Motivated Strategies for Learning Quetionnaire (MSLQ). The scale has 36 valid items with a reliability value of 0.897 . Mean while time management is measured by the Time Management Questionnaire (TMQ) scale. This scale has 16 valid items with a reliability value of 0.85 . Correlation test uses the correlation product moment technique which is done using SPSS 20 for Windows. The results showed that there was a positive relation between time management and self-regulated learning. The Correlation between time management and self-regulated learning obtained coefficient $\mathrm{r}=0.519$ with significance or $\mathrm{P}=0.000$. Based from the result shows that there is a significant positive relation between time management and self regulated learning amongst Medical students at the Malahayati University.

Keywords: time management, self regulation in learning 
Simaremare, Sandayanti, Silvia

\section{Pendahuluan}

Kedokteran merupakan ilmu yang terus berkembang dari waktu ke waktu. Hal ini membuat perubahan pada dunia pendidikan kedokteran. Konsil Kedokteran Indonesia mengenalkan Kurikulum Berbasis Kompetensi (KBK) dengan pendekatan SPICES (student centered, problem based, integrated, community based, elective, systematic (Lisiswanti, 2016).

Kurikulum Berbasis Kompetensi (KBK) berbeda dengan kurikulum yang sebelumnya dan kurikulum pada fakultas lain. Kurikulum ini memiliki karakteristik menggunakan sistem blok. Mahasiswa Fakultas Kedokteran akan menghadapi tingkat kesulitan studi dari sistem blok yang semakin meningkat. Dalam satu semester, mahasiswa mengikuti tiga hingga empat blok. Kegiatan pembelajaran yang dilakukan di Fakultas Kedokteran Universitas Malahayati mencakup proses kuliah, tutorial, praktikum laboratorium, pleno, serta keterampilan klinik atau clinical skill lab. Mahasiswa Fakultas Kedokteran dituntut untuk dapat menyelesaikan tugas dan mempelajari materi dari masing-masing kegiatan pembelajaran dalam waktu yang bersamaan. Sistem pembelajaran ini juga menuntut mahasiswa menjadi lebih aktif dalam mencari materi, metode serta waktu pembelajaran. Aktifitas pembelajaran tersebut berlangsung dari pagi hingga siang atau sore hari (Sari dkk, 2017).

Dari hasil wawancara terhadap beberapa mahasiswa Fakultas Kedokteran Universitas Malahayati angkatan 2018, sebagian besar dari mereka merasa kesulitan dalam menyesuaikan kegiatan proses belajar. Contohnya, dalam satu hari kegiatan proses belajar dapat meliputi proses tutorial, pleno, perkuliahan (lecture), praktikum laboratorium, serta keterampilan klinik atau clinical skill lab. Mereka dituntut untuk mampu mempersiapakan materi dan menyelesaikan tugas sebelum kegiatan proses belajar di mulai. Kegiatan proses belajar yang padat menyebabkan mereka kesulitan memanajemen waktu dalam menyelesaikan tugas. Banyak dari mereka juga belum mampu menetapkan prioritas belajar. Mereka belum mampu menentukan tugas yang harus diselesaikan terlebih dahulu sehingga mereka sering begadang untuk menyelesaikan tugastugasnya.

Beberapa peneliti mencoba meneliti mengenai hubungan manajemen waktu dengan regulasi diri dalam belajar. Penelitian terdahulu dilakukan oleh Mulyani (2013) pada mahasiswa Universitas Negeri Semarang. Hasil penelitian menunjukkan bahwa terdapat hubungan positif antara manajemen waktu dengan self regulated learning. Sejalan dengan itu, Muttaqin (2018) 
melakukan penelitian tentang hubungan manajemen waktu dengan regulasi diri dalam belajar. Penelitian yang dilakukan pada santri berstatus mahasiswa di Pondok Pesantren Al- Barokah Yogyakarta diperoleh hasil bahwa ada hubungan positif antara manajemen waktu dengan regulasi diri dalam belajar pada santri berstatus mahasiswa.

Regulasi diri dalam belajar adalah salah satu bentuk kemampuan individu dalam hal bagaimana cara mengontrol perilaku diri sendiri yang berhubungan dengan metakognitif, motivasi, dan perilaku (Dami, 2018). Perencanaan regulasi diri dalam belajar berhubungan dengan peran mahasiswa dalam menentukan penggunaan waktu dan sumber daya yang tersedia untuk tugas-tugas belajarnya (Sari dkk, 2017).

Boekaerts mengungkapkan bahwa banyak peneliti sepakat bahwa faktor yang paling mendasar dari regulasi diri dalam belajar adalah keinginan untuk mencapai tujuan. Atribut personal lain yang juga mempengaruhi regulasi diri dalam belajar antara lain: kesadaran akan penghargaan terhadap diri sendiri, keinginan untuk mencoba, komitmen, manajemen waktu, kesadaran akan metakognitif, penggunaan strategi yang efisien (Ambarsari, 2017).

Manajemen waktu merupakan pengaturan diri dalam menggunakan waktu seefektif dan seefisien mungkin dengan melakukan perencanaan, penjadwalan, memiliki kontrol waktu, membuat prioritas menurut kepentingannya, serta keinginan untuk terorganisasi yang dapat dilihat dari perilaku belajar dari seorang mahasiswa (Puspitasari, 2013).

Regulasi diri dalam belajar menjadi hal yang sangat penting untuk mahasiswa dalam proses belajar. Dengan adanya regulasi diri dalam belajar yang baik, individu akan menyadari, mempunyai rasa tanggung jawab, dan mengetahui cara belajar yang efektif bagi dirinya (Fasikhah \& Fatimah, 2013).

Berdasarkan uraian diatas peneliti tertarik untuk melakukan penelitian lebih lanjut terkait hubungan manajemen waktu dengan regulasi diri dalam belajar pada mahasiswa Fakultas Kedokteran Universitas Malahayati.

\section{Metode Penelitian}

Jenis penelitian ini adalah penelitian kuantitatif korelasional dengan menggunakan pendekatan cross sectonal dimana kedua variable yang di uji pada objek penelitian ini diukur atau dikumpulkan dalam waktu yang sama (Notoatmojo,2012). Penelitian dilakukan di Universitas Malahayati pada bulan Januari sampai Februari 2020. 
Populasi penelitian ini adalah mahasiswa angkatan 2018 yang menempuh pendidikan kedokteran di Fakultas Kedokteran Universitas Malahayati. Teknik sampling yang digunakan dalam penelitian ini adalah teknik random sampling. Sampel penelitian berjumlah 123 mahasiswa.

Dalam penelitian ini, data yang dikumpulkan berupa data primer. Instrumen penelitian ini berupa kuesioner yang terdiri dari 2 kelompok pernyataan, yaitu : Kuesioner Time Management Questionnaire (TMQ) digunakan sebagai alat pengumpul data untuk mengukur perilaku manajemen waktu mahasiswa, yang terdiri dari 16 pernyataan valid dan kuesioner Motivated Strategies for Learning Quetionnaire (MSLQ) digunakan untuk mengukur regulasi diri dalam belajar mahasiswa yang terdiri dari 36 pernyataan valid. Uji statistik yang digunakan dalam penelitian ini adalah uji spearman rank correlation karena data kedua variabel tidak terdistribusi normal.

Tabel 1

Distribusi frekuensi kategori manajemen waktu pada mahasiswa Fakultas Kedokteran Universitas Malahayati

\begin{tabular}{lcc}
\hline Manajemen Waktu & Frekuensi & Persentase (\%) \\
\hline Tidak Baik $(<53)$ & 49 & 39,8 \\
Baik $(\geq 53)$ & 74 & 60,2 \\
Total & 123 & 100 \\
\hline
\end{tabular}

Berdasarkan tabel diatas, variabel manajemen waktu dapat dikelompokkan menjadi kategori tidak baik dan baik. Dari 123 responden, didapatkan responden yang memiliki manajemen waktu kategori tidak baik sebanyak 49 orang atau 39,8\% dan kategori baik sebanyak 74 orang atau $60,2 \%$.

Tabel 2

Distribusi frekuensi kategori regulasi diri dalam belajar pada mahasiswa Fakultas Kedokteran Universitas Malahayati

\begin{tabular}{lcc}
\hline Regulasi Diri Dalam Belajar & Frekuensi & Persentase $(\boldsymbol{\%})$ \\
\hline Rendah $(36-72)$ & 11 & 8,9 \\
Sedang $(73-108)$ & 67 & 54,5 \\
Tinggi $(109-144)$ & 45 & 36,6 \\
Total & 123 & 100 \\
\hline
\end{tabular}

Berdasarkan tabel diatas, variabel regulasi diri dalam belajar dapat dikelompokkan menjadi kategori rendah, sedang dan tinggi. Dari 123 responden, didapatkan hasil responden yang 
memiliki regulasi diri kategori rendah sebanyak 11 orang atau 8,9\%, kategori sedang sebanyak 67 orang atau 54,5\% dan kategori tinggi sebanyak 45 orang atau 36,6\%.

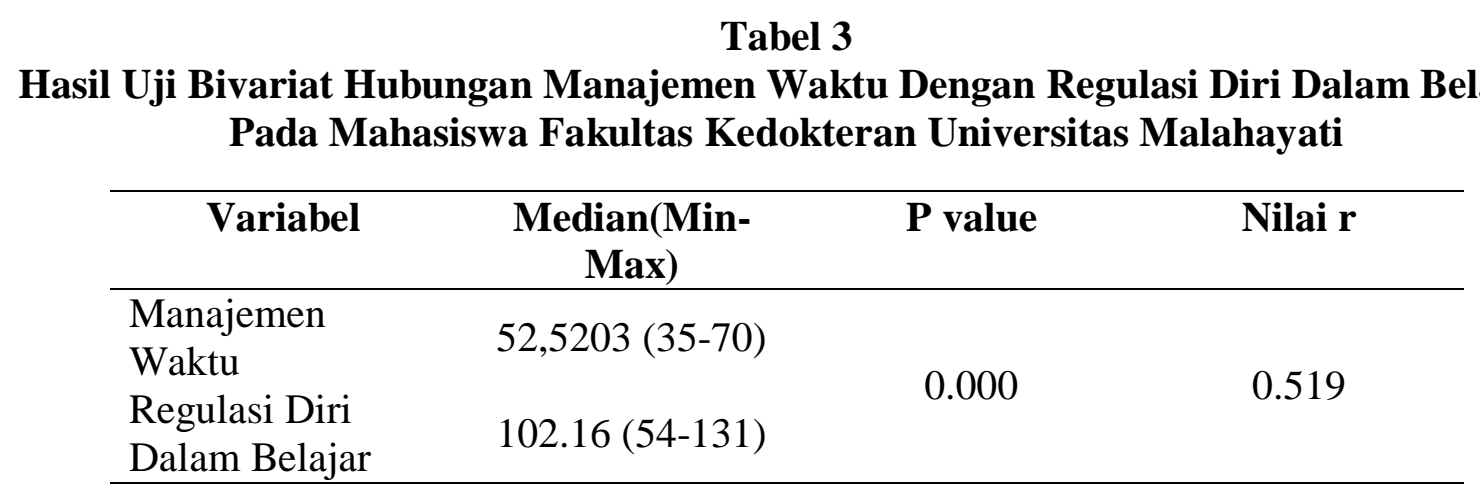

Berdasarkan data pada tabel diatas, diperoleh gambaran keadaan data pada skor variabel manajemen waktu dan regulasi diri dalam belajar. Pada variabel manajemen waktu dengan jumlah data 123 responden memiliki skor minimum 35,00, skor maksimum 70,00, dan rata-rata 52,5203. Pada variabel regulasi diri dalam belajar dengan jumlah data 123 responden memiliki skor minimum 54,00, skor maksimum 131,00, dan rata-rata 102,1626.

Uji hipotesa menggunakan uji spearman rank correlation pada 123 responden diperoleh hasil signifikansi atau $p$-value $=0,000$ ( $p$-value $<\alpha=0,05)$, maka hipotesis nihil (H0) yang menyatakan bahwa tidak ada hubungan antara manajemen waktu dengan regulasi diri dalam belajar pada mahasiswa ditolak. Selanjutnya, hipotesis alternatif (Ha) yang menyatakan bahwa ada hubungan antara manajemen waktu dengan regulasi diri dalam belajar pada mahasiswa diterima. (Sugiyono, 2013).

Koefisien korelasi pada penelitian ini memperoleh skor $(r)=0,519$, yang menunjukan bahwa arah hubungan yang dihasilkan menunjukan arah positif dengan kekuatan korelasi cukup kuat.

\section{Hasil dan Pembahasan}

Pengukuran manajemen waktu dilakukan kepada responden dengan menggunakan kuesioner yang berisikan 16 pertanyaan yang terdiri dari 3 indikator yaitu melakukan perencanaan jangka pendek, sikap terhadap waktu dan perencanaan jangka panjang. Hasil penelitian menunjukkan bahwa dari 123 responden, yang memiliki manajemen waktu kategori tidak baik sebanyak 49 orang atau 39,8\% dan kategori baik sebanyak 74 orang atau 60,2\%. Hasil 
tersebut menunjukkan bahwa sebagian besar mahasiswa Fakultas Kedokteran Universitas Malahayati angkatan 2018 memliki manajemen waktu yang baik. Manajemen waktu adalah kemampuan dalam melakukan perencanaan, penjadwalan dan melaksanakan tanggung jawab dengan pengelolaan waktu yang dimiliki seseorang dalam kehidupan sehari - hari (Puspitasari, 2018). Menurut teori britton dan tesser terdapat 3 komponen dalam manajemen waktu yaitu perencanaan jangka pendek, sikap terhadap waktu, dan perencanaan jangka panjang (Fitriah, 2014).

Mahasiswa yang tidak mampu memanajemen waktu yaitu mahasiswa yang sering mengisi waktu luangnya dengan kegiatan yang tidak bermanfaat, sering menunda mengerjakan tugas sehingga tugas tidak dapat selesai sesuai dengan deadline dan tidak mempunyai skala prioritas setiap tugas yang mahasiswa kerjakan (Puspitasari, 2018). Pengukuran regulasi diri dalam belajar dilakukan kepada responden dengan menggunakan kuesioner yang berisikan 36 pertanyaan. Hasil penelitian menunjukkan bahwa dari 123 responden, yang memiliki regulasi diri kategori rendah sebanyak 11 orang atau 8,9\%, kategori sedang sebanyak 67 orang atau $54,5 \%$ dan kategori tinggi sebanyak 45 orang atau 36,6\%. Dalam penelitian ini sebagian besar mahasiswa Fakultas Kedokteran angkatan 2018 Universitas Malahayati memiliki regulasi diri dalam belajar yang sedang dan tinggi yang artinya responden sudah memiliki pengaturan diri yang baik. Didapatkan juga responden dengan regulasi diri dalam belajar rendah sebanyak 11 responden.

Regulasi diri dalam belajar merupakan proses konstruktif aktif dimana mahasiswa menetapkan tujuan belajarnya dan kemudian berusaha untuk memonitor, mengatur, dan mengontrol kognisi, motivasi, dan tingkah lakunya agar sesuai dengan tujuannya dan kondisi kontekstual dari lingkungannya (Istia'dah, 2018).

Berdasarkan penelitian ini didapatkan regulasi diri dalam belajar mahasiswa Fakultas Kedokteran angkatan 2018 Universitas Malahayati berada dalam kategori sedang dan tinggi. Hal ini berarti bahwa mahasiswa dapat merencanakan, mengatur, dan mengontrol aktivitas belajar dengan baik, memiliki motivasi yang baik, dan dapat mengarahkan perilakunya dalam menyusun strategi belajar dengan baik, sehingga dapat mencapai tujuan belajar yang diinginkan. Zimmerman mengatakan bahwa individu yang mempunyai regulasi diri dalam belajar tinggi 
adalah individu yang efektif menggunakan potensinya untuk memonitor, mengatur dan mengontrol kognisi, motivasi, dan perilakunya dalam proses belajar (Mu'min, 2016).

Berdasarkan hasil penelitian uji hipotesa menggunakan uji spearman Rank Correlation pada 123 responden diperoleh hasil signifikansi atau $p$-value $=0,000(p$-value $<\alpha=0,05)$ yang menunjukan bahwa terdapat hubungan manajemen waktu dengan regulasi diri dalam belajar pada mahasiswa Fakultas Kedokteran angkatan 2018 di Universitas Malahayati, maka hipotesis nihil (H0) ditolak dan hipotesis alternative (Ha) diterima. Hipotesis ini menunjukan bahwa aspek manajemen waktu memiliki peran penting dalam meningkatkan regulasi diri dalam belajar pada mahasiswa Fakultas Kedokteran Universitas malahayati.

Kemudian diperoleh koefisien korelasi $(r)=0,519$ menunjukan bahwa arah hubungan yang dihasilkan menunjukan arah positif. Hubungan positif yang dimaksud ialah, semakin baik manajemen waktu maka semakin baik regulasi diri dalam belajar, begitu pula sebaliknya. Semakin buruk manajemen waktu semakin buruk pula regulasi diri dalam belajar mahasiswa.

Hubungan antara manajemen waktu dengan regulasi diri dalam belajar pada mahasiswa telah dibuktikan dari beberapa penelitian. Penelitian terdahulu dilakukan oleh Muttaqin (2018) melakukan penelitian tentang hubungan manajemen waktu dengan regulasi diri dalam belajar. Penelitian yang dilakukan pada santri berstatus mahasiswa di Pondok Pesantren Al- Barokah Yogyakarta diperoleh hasil bahwa ada hubungan positif antara manajemen waktu dengan regulasi diri dalam belajar pada santri berstatus mahasiswa. Semakin baik manajemen waktu maka semakin baik pula regulasi diri dalam belajar, sebaliknya semakin buruk manajemen waktu maka semakin buruk pula regulasi diri dalam belajarnya. Sejalan dengan itu, berdasarkan penelitian yang dilakukan oleh Mulyani (2013) pada mahasiswa Universitas Negeri Semarang. Hasil penelitian menunjukkan bahwa terdapat hubungan positif antara manajemen waktu dengan regulasi diri dalam belajar.

Manajemen waktu berperan dalam pembentukan regulasi diri dalam belajar. Manajemen waktu yang baik akan membentuk regulasi diri dalam belajar pada mahasiswa. Regulasi diri dalam belajar adalah proses individu mengenai pengaturan diri dalam belajar yang dilakukan secara mandiri dalam menampilkan serangkaian tindakan yang ditujukan untuk pencapaian target atau tujuan belajar dengan mengolah strategi dalam penggunaan kognisi, perilaku, dan motivasi (Mulyani, 2013). 
Mahasiswa yang tidak mampu mengarahkan dan mengatur tingkat prioritas dari kegiatan yang dilakukan adalah mahasiswa yang memiliki manajemen waktu yang buruk. Sebaliknya, bagi individu yang mempunyai kemampuan manajemen waktu yang baik, akan mampu mengatur dan merencanakan waktu untuk aktivitas sehari-hari secara efektif dan efisien, dengan menentukan tujuan, menyusun prioritas, membuat jadwal, meminimalisasi gangguan, dan mendelegasikan tugas (Puspitasari, 2018).

Zimmerman mengemukakan bahwa manajemen waktu merupakan salah satu factor yang mempengaruhi regulasi diri dalam belajar (Koro, 2017). Seseorang yang memiliki regulasi dalam belajar akan mengevaluasi diri terhadap pencapaian belajarnya, kemudian menganalisis hasil belajarnya, lalu membuat perencanaan pembelajarannya sendiri, dalam hal ini termasuk manajemen waktu dan cara belajar. Setelah itu menerapkan perencanaan tersebut. Selanjutnya memonitoring hasil dan memperbaiki strategi, kemudian mengevaluasi kembali apakah tujuan yang ditetapkan sudah tercapai atau belum. Demikian seterusnya dalam siklus regulasi diri dalam belajar. Regulasi diri dalam belajar diperlukan oleh setiap mahasiswa agar dapat mengarahkan dirinya untuk mencapai tujuan belajar (Mu'min, 2016).

\section{Kesimpulan}

Terdapat hubungan positif antara manajemen waktu dengan regulasi diri dalam belajar pada mahasiswa Fakultas Kedokteran Universitas Malahayati angkatan 2018. Korelasi manajemen waktu dengan regulasi diri dalam belajar diperoleh koefisien $r=0,519$ dengan signifikansi atau $p$-value $=0,000$.

Hasil penelitian ini diharapkan pihak Universitas atau fakultas dapat memberikan dorongan dan pembinaan kepada mahasiswa agar dapat meningkatkan kemampuan manajemen waktu. Dengan memperbaiki kemampuan manajemen waktu, diharapkan regulasi diri dalam belajar mahasiswa akan semakin baik. Bagi mahasiswa Fakultas Kedokteran angkatan 2018 Universitas Malahayati dapat melakukan evaluasi diri dalam manajemen waktu untuk setiap kegiatan kesehariannya. Penyusunan skala prioritas dengan tujuan mahasiswa dapat menentukan kegiatan yang paling penting agar dilakukan terlebih dahulu dan kegiatan yang tidak penting dapat di tunda sehingga tugas dapat diselesaiakan tepat waktu dan dilakukan secara terstruktur. Pembentukan kelompok belajar dapat dilakukan untuk memudahkan mahasiswa dalam memecahkan masalah atau kesulitan yang dihadapi dalam proses pembelajaran. Bagi peneliti 
selanjutnya dapat melakukan penelitian mengenai faktor - faktor lain yang mempengaruhi manajemen waktu maupun regulasi diri dalam belajar dan menggunakan subjek penelitian dengan jumlah lebih banyak dengan melibatkan beberapa angkatan untuk membandingkan hasilnya.

\section{Daftar pustaka}

Ambarsari, J., Ruhaena, L. and Uyun, Z., 2017. Efektivitas Pelatihan Manajemen Diri Untuk Meningkatkan Kemampuan Belajar Dengan Regulasi Diri (Self Regulated Learning) Siswa SMP (Doctoral dissertation, Universitas Muhammadiyah Surakarta).

Dami, Z.A. and Parikaes, P., 2018. Regulasi Diri Dalam Belajar Sebagai Konsekuen. Ciencias: Jurnal Penelitian dan Pengembangan Pendidikan, 1(1), pp.82-95.

Fasikhah, S.S. and Fatimah, S., 2013. Self-regulated learning (SRL) dalam meningkatkan prestasi akademik pada mahasiswa. Jurnal Ilmiah Psikologi Terapan, 1(1), pp.145-155.

Fitriah, N., 2014. Manajemen Waktu Belajar Mahasiswa Keperawatan dalam Melaksanakan Metode Problem Based Learning (PBL) di Universitas Islam Negeri Syarif Hidayatullah Jakarta.

Istia'dah, F.N.L., 2018. Komparasi Self Regulated Learning Pada Mahasiswa Yang Bekerja Dan Mahasiswa Yang Tidak Bekerja. Journal of Innovative Counseling: Theory, Practice, and Research, 2(01), pp.6-13.

Koro, M., Djamika, E.T. and Ramli, M., 2017, May. Self-Regulated Learning Sebagai Strategi Belajar Siswa Sekolah Dasar. In Seminar Nasional Teknologi Pembelajaran dan Pendidikan Dasar 2017 (pp. 788-795).

Lisiswanti, R., 2016. Pembelajaran di Fakultas Kedokteran: Pengenalan bagi Mahasiswa Baru. JK UNILA, jurnal kedokteran universitas lampung, vol 1 no 2, oktober 2016, 1(2), pp.399-403.

Mulyani, M.D., 2013. Hubungan antara manajemen waktu dengan self regulated learning pada mahasiswa. Educational psychology journal, 2(1).

Mu'min, S.A., 2016. Regulasi Diri dalam Belajar Mahasiswa yang Bekerja. Al-Ta'dib, 9(1), pp.120.

Notoatmodjo, S., 2012. Metodologi Penelitian Kesehatan, Rineka Cipta. Jakarta. Indonesia.

Puspitasari, S.A., 2018 Hubungan Manajemen Waktu Dengan Prestasi Belajar Mahasiswa Program Studi Ilmu Keperawatan Universitas Jember. 
Puspitasari, W., 2013. Hubungan antara manajemen waktu dan dukungan sosial dengan prestasi akademik mahasiswa yang bekerja. EMPATHY Jurnal Fakultas Psikologi, 2(1).

Sari, M.I., Lisiswanti, R. and Oktafany, O., 2017. Manajemen Waktu pada Mahasiswa: Studi Kualitatif pada Mahasiswa Kedokteran Universitas Lampung. Jurnal Kedokteran Universitas Lampung, 1(3), pp.525-529.

Sugiyono, P.D., 2013. Statistik untuk Penelitian. CV. Alvabeta Bandung. 